\title{
Sleep Quality of Mothers of Premature Infants after Neonatal Intensive Care Unit Discharge
}

\author{
Dae Seong Kim', Eui Kyung Choi', Jeong Hee Shin², Kyu Hee Park', \\ Jaehyung Cha ${ }^{3}$, Jang Hoon Lee ${ }^{4}$, Won Hee Seo', and Byung Min Choi ${ }^{1}$ \\ 'Department of Pediatrics, Korea University Ansan Hospital, Korea University College of Medicine, Ansan, Korea \\ ${ }^{2}$ Department of Pediatrics, Korea University Guro Hospital, Korea University College of Medicine, Seoul, Korea \\ ${ }^{3}$ Medical Science Research Center, Korea University Ansan Hospital, Ansan, Korea \\ ${ }^{4}$ Department of Pediatrics, Ajou University School of Medicine, Suwon, Korea
}

\begin{abstract}
Objectives: Advanced clinical management has increased the survival rate of premature infants. Mothers of premature infants have more concerns about their infant's health, which may impair their sleep quality. This study aimed to investigate the sleep quality of Korean mothers of premature infants after neonatal intensive care unit (NICU) discharge. Methods: Face-to-face interviews were conducted for 90 mothers of infants corrected aged 0-12 months who were born at $<37$ weeks of gestation and had been discharged from the NICU. The questionnaire consisted of the general background of mother including family, employment status and medical history of infants; Pittsburgh Sleep Quality Index (PSQI) to assess the mother's sleep status; the Brief Infant Sleep Questionnaire to assess the infant's sleep status. Results: The mean global PSQI score was 8.0 \pm 4.0. In total, 70/90 mothers were identified as poor sleepers (PSQI scale $>5$ ). There was significant difference in premature infants' age, corrected age, weight, duration since NICU discharge, and frequency and duration of night waking. However, it did not show significance in maternal factor, familial background, medical condition of infant. Conclusion: Most Korean mothers of premature infants experienced poor sleep quality even after their infants were discharged. We found that mothers with good sleep quality had premature infant of older age and more body weight and longer duration since NICU discharge. These findings indicate that at least in the early stages of discharge of premature infant, sleep education for the mother of the premature infant is necessary.
\end{abstract}

Key Words: Mother; Premature infants; Sleep quality

Received: May 11, 2020 Revised: June 1, 2020 Accepted: June 2, 2020

Corresponding author: Won Hee Seo, MD, PhD, Department of Pediatrics, Korea University Ansan Hospital, Korea University College of Medicine, 123 Jeokgeumro, Danwon-gu, Ansan 15355, Korea.

Tel: 82-31-412-5096, Fax: 82-31-405-8591, E-mail: wonny508@korea.ac.kr

(a) This is an Open Access article distributed under the terms of the Creative Commons Attribution Non-Commercial License (https://creativecommons.org/licenses/bync/4.0) which permits unrestricted non-commercial use, distribution, and reproduction in any medium, provided the original work is properly cited.

\section{INTRODUCTION}

In recent decades, the rates of preterm birth (born before 37 weeks of gestation), the most frequent cause of infant mortality, have increased worldwide, including in Korea [1,2]. Although the survival of premature infants is improving because of advances in clinical management, premature infants are physiologically and developmentally immature and are at a higher risk of morbidity and mortality than full-term infants $[3,4]$.

Mothers of premature infants have more concerns about their infant's health and feel that their caregiving burden is greater after infants go home, compared to mothers of full-term infants. The majority of mothers described premature birth as a trau- matic stressor, which may lead to various emotional responses such as depression and insomnia, regardless of significant complications [5]. Swedish parents have reported negative effects on their sleep during their infants' hospitalization in the neonatal intensive care unit (NICU) because of anxiety-induced stress [6]. These stress and depression may negatively influence sleep. Importantly, mothers of premature infants may not achieve the sleep quality necessary for adequate daytime functioning.

Among the subjective methods of sleep quality, the Pittsburgh Sleep Quality Index (PSQI), a self-reported questionnaire used worldwide, measures sleep quality during the previous month. The PSQI has been translated and validated in many languages, including Korean, and is used in many clinical sleep studies [7,8]. 
Sleep quality have been influenced by the sociocultural factor as well as individual factors such as infant' condition or familial background. However, limited studies have assessed maternal sleep quality after NICU discharge in Korea.

The aim of this study is to investigate the sleep quality of Korean mothers of premature infants after NICU discharge.

\section{METHOD}

Face-to-face interviews were conducted for 90 mothers of premature infants corrected age $0-12$ months old who were born before 37 weeks of gestation and had been discharged from NICU.

\section{Study subjects}

This study was conducted at three tertiary hospitals from August to November 2019.

The questionnaire consisted of three part: 1) the PSQI to assess the mother's sleep status; 2) the Brief Infant Sleep Questionnaire (BISQ) to assess the infant's sleep status; and 3) questionnaires to assess the infant's current age, gestational age, corrected age, cohabitating family members, birth order, age at NICU discharge. Serious medical conditions during hospitalization and complications after NICU discharge were obtained from medical record. Serious medical conditions included sepsis, need for cardiopulmonary resuscitation, grade 3-4 intraventricular hemorrhage (IVH), hydrocephalus surgery, severe retinopathy of prematurity (ROP), necrotizing enterocolitis surgery, inguinal hernia surgery, patent ductus arteriosus surgery, severe infection, bronchial pulmonary dysplasia (BPD), hypoxic ischemic encephalopathy (HIE). Sequelae of prematurity included growth retardation, insufficient oral intake, BPD, severe IVH, HIE, ROP, symptoms of genetic disorders, osteomalacia, and rickets. For twin mother, one questionnaire was asked.

This study was approved by the ethics committee of Korea University Ansan Hospital (No. 2019AS0178). Written informed consent was obtained from all participants.

\section{Assessment of infant sleep using the BISQ}

The BISQ includes 11 subjective and objective infant sleep questions about nocturnal sleep duration, daytime sleep duration, number of night awakenings, duration of nocturnal wakefulness, nocturnal sleep onset time, settling time, method of falling asleep, sleep location, and preferred body position [9]. The mothers were instructed to refer to the infant's sleep patterns during the previous week. In the case of twin, sleep questionnaire for smaller infants was asked.

\section{Assessment of maternal sleep using the PSQI}

The PSQI is a widely used and well-validated self-reporting tool that assesses sleep disturbances in adults. The 19-item PSQI measures seven components: subjective sleep quality, sleep latency, sleep duration, habitual sleep efficiency, sleep disturbances, sleeping medication use, and daytime functioning. It is designed to use the total score added by converting the score for each area. The total score ranges from 0 to 21 points, and the higher the score, the lower the quality of sleep. According to the criteria of Buysse et al. [10], this study used the established cutoff a score of $>5$ to depict poor sleep quality. In this study, Korean version was used [7].

\section{Statistical analysis}

Statistical analysis was performed using SPSS for Windows (version 25.0; IBM Corp., Armonk, NY, USA). To compare two group means, the independent two-sample t-test or Mann-Whitney test was used with Bonferroni correction. Further, analysis of variance or the Kruskal-Wallis test was used to analyze the equality of the means for more three groups. The chi-square test was used to analyze the association between good sleep (PSQI score $\leq 5$ ) and bad sleep (PSQI score $>5$ ).

Multiple logistic regression analysis was used to estimate effect of various factors on the mother's sleep quality. Results are presented as odds ratios (OR) and 95\% confidence intervals (95\% CI). p-values $<0.05$ were considered statistically significant.

\section{RESULTS}

\section{Demographic characteristics}

The study included 90 mothers with a mean age of $35.3 \pm 4.7$ years (range, $22-50$ years).

The 90 premature infants had a mean gestational age of $32.9 \pm$ 2.9 weeks (range, 25.14-36.86 weeks); 52 (57.8\%) were boys. Their mean corrected age at interview was $3.9 \pm 4.0$ months (range, -1.43-12.09 months) and the mean duration since discharge was $4.7 \pm 4.0$ months (range, $0.1-12.8$ months). The demographic characteristics of the mothers and the clinical information about their premature infant are presented in Table 1.

\section{Maternal sleep assessment}

The mean sleep duration was $6.6 \pm 1.9$ hours, the mean sleep latency was $25.9 \pm 22.8$ minutes, and the mean sleep efficacy was $83.6 \pm 19.2 \%$. The sleep duration reported by mother was different from the sleep duration calculated by went to bed time, waking time, and sleep latency ( $6.6 \pm 1.9$ vs. $5.4 \pm 1.9$ hours). Maternal sleep characteristics are present in Table 2.

\section{Maternal sleep quality in PSQI scores}

The mean global PSQI score was $8.0 \pm 4.0$ (range, 1-17). Each component of PSQI are presented in Table 3.

In total, 70 of $90(77.8 \%)$ mothers were poor sleepers according to the PSQI (score $>5$ ). There were significant differences between mothers with good sleep quality and poor sleep quality in infant's age, corrected age, current weight, duration since discharge, and frequency and duration of night waking (Table 4). However, there were no significant differences in gestational age, familial background including family type, number of children, maternal em- 
Table 1. Demographic characteristics of Korean parents and preterm infants $(n=90)$

\begin{tabular}{|c|c|}
\hline Variables & Values \\
\hline \multicolumn{2}{|l|}{ Maternal demographics } \\
\hline Age $(y r)(n=86)$ & $35.3 \pm 4.7$ \\
\hline \multicolumn{2}{|l|}{ Employment status } \\
\hline Unemployed & $64(71.1)$ \\
\hline Full time & $23(25.6)$ \\
\hline Part time & $3(3.3)$ \\
\hline \multicolumn{2}{|l|}{ Type of pregnancy } \\
\hline Spontaneous & $63(70.0)$ \\
\hline Artificial insemination & $6(6.7)$ \\
\hline In vitro fertilization and embryo transfer & $21(23.3)$ \\
\hline \multicolumn{2}{|l|}{ Family type } \\
\hline Nuclear family & $79(87.8)$ \\
\hline Large family & $11(12.2)$ \\
\hline \multicolumn{2}{|l|}{ Demographics of premature infants } \\
\hline \multicolumn{2}{|l|}{ Sex } \\
\hline Male & $52(57.8)$ \\
\hline Female & $38(42.2)$ \\
\hline Gestational age (wk) & $32.9 \pm 2.9$ \\
\hline Age (month) & $5.8 \pm 4.2$ \\
\hline Corrected age (month) & $3.9 \pm 4.0$ \\
\hline Birth weight (kg) & $2.0 \pm 0.7$ \\
\hline Current weight (kg) & $6.4 \pm 2.5$ \\
\hline \multicolumn{2}{|l|}{ Birth-order } \\
\hline First infant & $42(46.7)$ \\
\hline Second infant & $36(40.0)$ \\
\hline Third infant & $10(11.1)$ \\
\hline More than three infant & $2(2.2)$ \\
\hline Duration of stay in hospital (wk) $(n=86)$ & $4.5 \pm 3.8$ \\
\hline Duration since NICU discharge (month) & $4.7 \pm 4.0$ \\
\hline \multicolumn{2}{|l|}{ Serious medical condition during hospitalization } \\
\hline None & $14(15.6)$ \\
\hline Serious condition & $76(84.4)$ \\
\hline \multicolumn{2}{|l|}{ Complications after NICU discharge } \\
\hline None & $58(64.4)$ \\
\hline Sequela of preterm infants & $15(16.7)$ \\
\hline Twin & $17(18.9)$ \\
\hline
\end{tabular}

Data are expressed as mean \pm standard deviation or number (\%). Missing data were excluded in each variables. NICU: neonatal intensive care unit

ployment status. In addition, there were no differences in infant sleep status, serious medical condition during hospitalization, and sequelae of prematurity.

In multiple logistic regression analysis, maternal sleep quality was related to corrected age of premature infant $(\mathrm{p}=0.034$, OR $0.85,95$ CI 0.74-0.99).

\section{DISCUSSION}

In this study, $77.8 \%$ of mothers of premature infants had poor sleep quality according to the PSQI. Mothers of premature infants
Table 2. Sleep characteristics of mother $(n=90)$

\begin{tabular}{lc} 
& Values \\
Sleep duration $(\mathrm{h})$ & $6.6 \pm 1.9$ \\
Calculated sleep duration $(\mathrm{h})$ & $5.4 \pm 1.9$ \\
Sleep onset latency $(\mathrm{min})$ & $25.9 \pm 22.8$ \\
Time to bed $(\mathrm{h})$ & $22.7 \pm 0.7$ \\
Wake up time $(\mathrm{h})$ & $6.9 \pm 1.5$ \\
Sleep efficiency $(\%)$ & $83.6 \pm 19.2$ \\
\hline
\end{tabular}

Data are expressed as mean \pm standard deviation.

Table 3. Global and component PSQI $(n=90)$

\begin{tabular}{lc} 
PSQI total score & Values \\
Component scores & $8.0 \pm 4.0$ \\
$\quad$ Subjective sleep quality & \\
Sleep latency & $1.1 \pm 1.0$ \\
Sleep duration & $1.1 \pm 1.1$ \\
Habitual sleep efficiency & $1.8 \pm 1.0$ \\
Sleep disturbance & $0.8 \pm 1.2$ \\
Use of sleep medication & $1.1 \pm 0.6$ \\
Daytime functioning & $1.6 \pm 0.8$ \\
\hline
\end{tabular}

Data are expressed as mean \pm standard deviation.

with younger current and corrected ages, lower current weight, shorter duration since discharge, and more night waking during sleep had worse maternal sleep quality $(p<0.05)$. There were no significant differences in gestational age, family type, number of children, serious medical conditions during hospitalization, or sequelae of prematurity. In this study, we found that maternal sleep quality was more closely related to premature infant age and weight than the familial background or complications related to prematurity. To our knowledge, this is the first study to investigate the sleep quality in Korean mothers of premature infants after NICU discharge.

In this study, the mean sleep duration by reported mothers was $6.6 \pm 1.9$ hours a day and the mean sleep latency was $25.9 \pm 22.8 \mathrm{~min}-$ utes. And calculated sleep duration by went to bed time, waking time and sleep latency was $5.4 \pm 1.9$ hours. This result is less than the mean sleep duration of 7.7 hours for Korean mothers of 0-6 aged children reported in other study [11]. Even in healthy adults, partial sleep deprivation of 5-6 hours of sleep duration has been shown to result in daytime sleepiness and a negative mood [12]. When it continues for 1-2 weeks, it can lead to cognitive impairment [13]. These mental effects of poor sleep quality negatively affect the mothers' well-being, which negatively affects their infant [14]. Therefore, sufficient sleep is important for ensuring quality care for premature infants. On regarding the difference between reported sleep duration and the calculated sleep duration, mothers of premature infant may not realize that their actual sleep duration is shorter. This indicated that mothers may not aware of their sleep status which may worsens the sleep quality. An Australian study have reported that educational intervention is effective in preventing postpartum depression (PPD) and sleep disturbance [15]. 
Therefore, it is helpful to educate mothers of premature infant about adequate sleep duration and a healthy sleeping environment.

Maternal subjective sleep quality is closely related to maternal depressive symptoms and infant caretaking at night [16]. PPD is common and has serious implications for a mother and her newborn. A possible link between placental corticotrophin-releasing hormone and PPD has been hypothesized, but empirical evidence is lacking [17]. Moreover, when premature infants remain hospitalized for several weeks or months, the potential cumulative effect of poor parent sleep on their ability to retain complex health information and participate in decision making is of particular concern [18]. Studies have shown that parents of premature infants had heightened levels of depression, anxiety, and stress compared to parents of full-term infants [19,20]. Carter et al. [21] have reported a dose-response relationship between the degree of prematurity and depressive symptoms, with higher depression scores in mothers of infants born at $<33$ weeks of gestation than in mothers of infants born at 33-35 weeks of gestation and mothers of full-term infants.

Stress has been known one of the most important risk factors of

Table 4. Comparisons of characteristics between good sleep quality and poor sleep quality of the mothers of premature infant according to the PSQI score $(n=90)$

\begin{tabular}{|c|c|c|c|}
\hline & $\begin{array}{l}\text { Good sleep quality } \\
\text { PSQI } \leq 5(n=20)\end{array}$ & $\begin{array}{l}\text { Poor sleep quality } \\
\text { PSQI }>5(n=70)\end{array}$ & p-value \\
\hline \multicolumn{4}{|l|}{ Maternal factor } \\
\hline Age $(y r)(n=86)$ & $34.85 \pm 4.88$ & $35.39 \pm 4.65$ & 0.652 \\
\hline Employment status & & & 0.146 \\
\hline Unemployed & $17(18.9)$ & $47(52.2)$ & \\
\hline Full time & $2(2.2)$ & $21(23.3)$ & \\
\hline Part time & $1(1.1)$ & $2(2.2)$ & \\
\hline Family type & & & 0.114 \\
\hline Nuclear family & $20(22.2)$ & $59(65.6)$ & \\
\hline Large family & $0(0)$ & $11(12.2)$ & \\
\hline Type of pregnancy & & & 0.148 \\
\hline Spontaneous & $14(15.6)$ & $49(54.4)$ & \\
\hline Artificial insemination & $3(3.3)$ & $3(3.3)$ & \\
\hline In vitro fertilization and embryo transfer & $3(3.3)$ & $18(20.0)$ & \\
\hline Birth-order & & & 0.658 \\
\hline First infant & $11(12.2)$ & $31(34.4)$ & \\
\hline Second infant & $6(6.7)$ & $30(33.3)$ & \\
\hline Third infant & $3(3.3)$ & $7(7.8)$ & \\
\hline More than three infant & $0(0)$ & $2(2.2)$ & \\
\hline \multicolumn{4}{|l|}{ Premature infant factor } \\
\hline Sex & & & 0.291 \\
\hline Male & $9(10.0)$ & $43(47.8)$ & \\
\hline Female & $11(12.2)$ & $27(30.0)$ & \\
\hline Age (month) & $8.12 \pm 4.36$ & $5.15 \pm 3.88$ & $0.011^{*}$ \\
\hline Gestational age (wk) & $32.76 \pm 3.03$ & $32.94 \pm 2.94$ & 0.884 \\
\hline Corrected age (month) & $6.13 \pm 4.24$ & $3.27 \pm 3.66$ & $0.011^{*}$ \\
\hline Birth weight (kg) & $1.90 \pm 5.62$ & $2.03 \pm 7.00$ & 0.470 \\
\hline Current weight (kg) & $7.51 \pm 2.31$ & $5.15 \pm 3.88$ & $0.025^{*}$ \\
\hline Duration of stay in hospital (wk) $(n=86)$ & $4.36 \pm 3.97$ & $4.50 \pm 3.74$ & 0.894 \\
\hline Duration since NICU charge (month) & $7.04 \pm 4.18$ & $4.09 \pm 3.66$ & $0.007^{*}$ \\
\hline Complications after hospitalization & & & 0.090 \\
\hline None & $17(18.9)$ & $41(45.6)$ & \\
\hline Sequela of preterm birth & $2(2.2)$ & $13(14.4)$ & \\
\hline Twin & $1(1.1)$ & $16(17.8)$ & \\
\hline Serious medical condition during hospitalization & & & 1.000 \\
\hline None & $3(3.3)$ & $11(12.2)$ & \\
\hline Serious condition & $17(18.9)$ & $59(65.6)$ & \\
\hline Frequency of night waking of infants & $1.20 \pm 1.20$ & $2.17 \pm 1.50$ & $0.008^{*}$ \\
\hline Duration of nocturnal awakening of infants (min) & $13.68 \pm 20.0$ & $41.8 \pm 55.8$ & $0.003^{*}$ \\
\hline
\end{tabular}

Data are expressed as mean \pm standard deviation or number (\%). Missing data were excluded in each variables. ${ }^{*} \mathrm{p}<0.05$ 
impaired sleep. Stress experienced by mothers of an infant in the NICU is concomitantly associated with sleep disturbance, fatigue, depression, and poor quality of life [22,23]. Lee et al. [24] has proposed the following overall stress-sleep-health path; 1) stress would directly contribute to sleep disturbance; 2) disturbed sleep would mediate the effect of stress on fatigue and poor quality of life; and 3) fatigue would mediate the correlation between stress, depression, and sleep disturbance in addition to the direct contribution to adverse quality of life.

Maternal separation anxiety is defined as an unpleasant emotional state that involves feelings of guilt, worry, and sadness that accompany short-term separation from the child [25]. Korean mothers' feelings about premature infants have reported that emotional distress and concern are large, which can be attributed to cultural background [26]. Higher levels of separation anxiety were associated with oversensitivity to physical proximity at bedtime and more involvement during the course of the night $[27,28]$. Separation anxiety of mother may be caused by abnormal control of breathing during sleep and sleep apnea of prematurity. In particular, premature infants are at a risk of sleep-related life-threatening events such as sudden infant death syndrome. These psychological causes of mothers would have further poor sleep quality through bidirectional paths.

Infants' sleep patterns are problematic and include night waking with crying, a common concern for parents of infants. In previous studies, the mean frequency of nocturnal waking of full-term infants was $0.8 /$ night (range, $0-2.9 /$ night); just over half (55\%) of the participating mothers reported that their premature infants woke 2.1 times per night for a mean 45.7 minutes per night, which is similar to our findings $[29,30]$. We found that the frequency and duration of night wakings of premature infants affected the quality of the maternal sleep. Frequent nocturnal waking negatively impacts infant and family functioning [31,32]. Also, maternal sleep quality may cause problems with parenting quality. King et al. [33] have reported that mothers with poorer sleep continuity have decreased sensitivity toward their infants.

The findings of abovementioned studies support those of our study $-77.8 \%$ of mothers of premature infants experienced poor sleep quality. However, it is not yet known how long the premature infant's mother would have poor sleep quality. We found significant differences in duration since NICU discharge ( $7.04 \pm 4.18$ vs. $4.09 \pm 3.66$ months, $\mathrm{p}<0.05)$. This finding is consistent with those of a study that reported a lower rate of night waking at 5 months of age among infants after NICU discharge compared with a term controls; however, by $25-45$ months of age, there were no differences [34]. O'Brien et al. [35] have reported that there is no statistically significant decrease in depression score after discharge. However, one study has reported that mothers of premature infants had higher parental stress scores than mothers of term infants at 1-2 years of age and that mothers of very low birth weight premature infants had behavioral problems at 3 years of age [36]. These results including our finding suggest that better sleep quality can be expected as premature infant grows.
Assessment methods of sleep in infants and adults can be subjective or objective. Subjective methods include sleep diaries, self-reported questionnaires, and structured interviews. There are many questionnaires for child and adult, some of which are validated such as the BISQ and PSQI, that assess sleep duration, onset time, and sleep latency in the sleeping environment. The PSQI, one of the most widely used measurement tools for assessing sleep status in adults, is recognized for its reliability and validity in several languages, including Korean [7]. The PSQI has the advantage of calculating total and seven area-specific scores, and cut-off points of global PSQI scores are reported as 5 points; hence, PSQI scores in sleep studies can be cross-culturally compared. In addition, sleep state and quality can be evaluated in more detail and have explanatory power through analysis of the sleep measurement dimension for each of the seven areas [37]. However, the method proposed is complicated; hence, it is difficult and time-consuming to obtain a sleep score.

This study has some limitations. We used self-reported questionnaires of infant and maternal sleep and not an objective tool. A previous study has suggested that infant-induced maternal sleep disturbances resulting from frequent infant nocturnal waking might be more relevant to the mother's perceived sleep quality than the total amount of time she spent awake at night [16]. Therefore, regarding sleep quality related to subjective feelings such as stress, studies using subjective methods such as self-reported questionnaires may be better reflected than studies using objective methods. Further studies should include objective and subjective methods for assessing sleep quality. Another, sleep quality may be influenced by many other factors such as mental problem and socioeconomic status that were not identified or controlled for in this study. Especially, depression and anxiety are well-known factor that may also require future research.

In conclusion, most mothers of premature infants experienced poor sleep quality even after their infants were discharged from the NICU. We found that mothers with good sleep quality had older age and more body weight and longer duration since NICU discharge. These findings indicate that at least in the early stages of discharge of premature infant, sleep education for the mother of the premature infant is necessary.

\section{Acknowledgments}

This research was supported by a grant of the Korea Health Technology R\&D Project through the Korea Health Industry Development Institute (KHIDI), funded by the Ministry of Health \& Welfare, Republic of Korea (Grant number: HI19C0273).

\section{Conflicts of Interest}

The authors have no potential conflicts of interest to disclose.

\section{Author Contributions}

Conceptualization: Won Hee Seo. Formal analysis: Jaehyung Cha. Investigation: Eui Kyung Choi, Jeong Hee Shin. Methodology: Byung Min Choi, Eui Kyung Choi, Jeong Hee Shin, Kyu Hee 
Park, Jang Hoon Lee. Supervision: Won Hee Seo. Writing-original draft: Dae Seong Kim. Writing_review \& editing: Byung Min Choi.

\section{ORCID iDs}

Won Hee Seo (D)

https://orcid.org/0000-0001-7628-7982

Dae Seong Kim (D)

https://orcid.org/0000-0002-9390-533X

\section{REFERENCES}

1. Zeitlin J, Szamotulska K, Drewniak N, Mohangoo AD, Chalmers J, Sakkeus L, et al. Preterm birth time trends in Europe: a study of 19 countries. BJOG 2013;120:1356-1365.

2. Moon JY, Hahn WH, Shim KS, Chang JY, Bae CW. Changes of maternal age distribution in live births and incidence of low birth weight infants in advanced maternal age group in Korea. Korean J Perinatol 2011;22:30-36.

3. Lee JH, Youn Y, Chang YS. Short- and long-term outcomes of very low birth weight infants in Korea: Korean Neonatal Network update in 2019. Clin Exp Pediatr 2020 Feb 5 [Epub]. Available at: https://doi.org/10.3345/ cep.2019.00822.

4. Simmons LE, Rubens CE, Darmstadt GL, Gravett MG. Preventing preterm birth and neonatal mortality: exploring the epidemiology, causes, and interventions. Semin Perinatol 2010;34:408-415.

5. Jubinville J, Newburn-Cook C, Hegadoren K, Lacaze-Masmonteil T. Symptoms of acute stress disorder in mothers of premature infants. Adv Neonatal Care 2012;12:246-253.

6. Edéll-Gustafsson U, Angelhoff C, Johnsson E, Karlsson J, Mörelius E. Hindering and buffering factors for parental sleep in neonatal care. A phenomenographic study. J Clin Nurs 2015;24:717-727.

7. Sohn SI, Kim DH, Lee MY, Cho YW. The reliability and validity of the Korean version of the Pittsburgh Sleep Quality Index. Sleep Breath 2012;16: 803-812.

8. Choi HJ, Kim SJ, Kim BJ, Kim IJ. Korean versions of self-reported sleep questionnaires for research and practice on sleep disturbance. Korean J Rehabil Nurs 2012;15:1-10.

9. Sadeh A. A brief screening questionnaire for infant sleep problems: validation and findings for an Internet sample. Pediatrics 2004;113:e570-e577.

10. Buysse DJ, Reynolds CF 3rd, Monk TH, Berman SR, Kupfer DJ. The Pittsburgh Sleep Quality Index: a new instrument for psychiatric practice and research. Psychiatry Res 1989;28:193-213.

11. Mindell JA, Sadeh A, Kwon R, Goh DY. Cross-cultural comparison of maternal sleep. Sleep 2013;36:1699-1706.

12. Walsleben JA, Kapur VK, Newman AB, Shahar E, Bootzin RR, Rosenberg $\mathrm{CE}$, et al. Sleep and reported daytime sleepiness in normal subjects: the Sleep Heart Health Study. Sleep 2004;27:293-298.

13. Sadeh A, Flint-Ofir E, Tirosh T, Tikotzky L. Infant sleep and parental sleeprelated cognitions. J Fam Psychol 2007;21:74-87.

14. Tikotzky L, Chambers AS, Gaylor E, Manber R. Maternal sleep and depressive symptoms: links with infant Negative Affectivity. Infant Behav Dev 2010;33:605-612.

15. Kempler L, Sharpe L, Bartlett D. Sleep education during pregnancy for new mothers. BMC Pregnancy Childbirth 2012;12:155.

16. Gress JL, Chambers AS, Ong JC, Tikotzky L, Okada RL, Manber R. Maternal subjective sleep quality and nighttime infant care. J Reprod Infant Psychol 2010;28:384-391.

17. Yim IS, Glynn LM, Dunkel-Schetter C, Hobel CJ, Chicz-DeMet A, Sand- man CA. Risk of postpartum depressive symptoms with elevated corticotropin-releasing hormone in human pregnancy. Arch Gen Psychiatry 2009; 66:162-169.

18. Lee SY, Lee KA, Rankin SH, Weiss SJ, Alkon A. Sleep disturbance, fatigue, and stress among Chinese-American parents with ICU hospitalized infants. Issues Ment Health Nurs 2007;28:593-605.

19. Pace CC, Spittle AJ, Molesworth CM, Lee KJ, Northam EA, Cheong JL, et al. Evolution of depression and anxiety symptoms in parents of very preterm infants during the newborn period. JAMA Pediatr 2016;170:863-870.

20. Vigod SN, Villegas L, Dennis CL, Ross LE. Prevalence and risk factors for postpartum depression among women with preterm and low-birth-weight infants: a systematic review. BJOG 2010;117:540-550.

21. Carter JD, Mulder RT, Bartram AF, Darlow BA. Infants in a neonatal intensive care unit: parental response. Arch Dis Child Fetal Neonatal Ed 2005;90: F109-F113.

22. Lee SY, Kimble LP. Impaired sleep and well-being in mothers with lowbirth-weight infants. J Obstet Gynecol Neonatal Nurs 2009;38:676-685.

23. Lee SY, Hsu HC. Stress and health-related well-being among mothers with a low birth weight infant: the role of sleep. Soc Sci Med 2012;74:958-965.

24. Lee KA. Impaired sleep. In: Carrieri-Kohlman V, Lindsey AM, West CM, editors. Pathophysiological phenomena in nursing: human responses to illness. St. Louis, MO: Saunders, 2003, p. 363-385.

25. Hock E, McBride S, Gnezda MT. Maternal separation anxiety: mother-infant separation from the maternal perspective. Child Dev 1989;60:793-802.

26. Lee I, Norr KF, Oh K. Emotional adjustment and concerns of Korean mothers of premature infants. Int J Nurs Stud 2005;42:21-29.

27. Scher A, Blumberg O. Night waking among 1-year olds: a study of maternal separation anxiety. Child Care Health Dev 1999;25:323-334.

28. Scher A. Maternal separation anxiety as a regulator of infants' sleep. J Child Psychol Psychiatry 2008;49:618-625.

29. Galland BC, Taylor BJ, Elder DE, Herbison P. Normal sleep patterns in infants and children: a systematic review of observational studies. Sleep Med Rev 2012;16:213-222.

30. Ali R, Hall W, Warnock F, Wong S, Ratner P. Quality of preterm infants night sleep: and online community-based survey of maternal factors and perceptions of infants nighttime awakenings and sleep problems. Int J Advan Nurs Studies 2014;3:59-64.

31. Bernier A, Carlson SM, Bordeleau S, Carrier J. Relations between physiological and cognitive regulatory systems: infant sleep regulation and subsequent executive functioning. Child Dev 2010;81:1739-1752.

32. Lam P, Hiscock H, Wake M. Outcomes of Infant sleep problems: a longitudinal study of sleep, behavior, and maternal well-neing. Pediatrics 2003;111: e203-e207.

33. King LS, Rangel E, Simpson N, Tikotzky L, Manber R. Mothers' postpartum sleep disturbance is associated with the ability to sustain sensitivity toward infants. Sleep Med 2020;65:74-83.

34. Wolke D, Meyer R, Ohrt B, Riegel K. The incidence of sleeping problems in preterm and fullterm infants discharged from neonatal special care units: an epidemiological longitudinal study. J Child Psychol Psychiatry 1995;36: 203-225.

35. O’Brien M, Asay JH, McCluskey-Fawcett K. Family functioning and maternal depression following premature birth. J Reprod Infant Psychol 1999; 17:175-188.

36. Huhtala M, Korja R, Lehtonen L, Haataja L, Lapinleimu H, Rautava P; PIPARI Study Group. Parental psychological well-being and behavioral outcome of very low birth weight infants at 3 years. Pediatrics 2012;129:e937e944.

37. Casement MD, Harrington KM, Miller MW, Resick PA. Associations between Pittsburgh Sleep Quality Index factors and health outcomes in women with posttraumatic stress disorder. Sleep Med 2012;13:752-758. 